\title{
EN TORNO A FILOSOFÍA, RETÓRICA Y POLÍTICA
}

\author{
Joaquín Barceló \\ Universidad Andrés Bello
}

\begin{abstract}
Resumen: A mediados del siglo XX el filósofo Ernesto Grassi sorprendió con la publicación de una tesis según la cual la retórica es filosofía. En el presente artículo se intenta describir los antecedentes de que pudo servirse para fundamentar su tesis y aclarar a la vez el significado de ella. Palabras clave: filosofía, retórica, verosimilitud, humanismo, racionalismo.

Recibido: mayo 2013; aceptado: mayo 2013.
\end{abstract}

PHILOSOPHY, RHETORIC AND POLITICS

Abstract: In the mid-20th century, the philosopher E. Grassi surprised everyone with the publication of a thesis according

JoAquín Barceló Larraín (1927-2014). Destacado profesor de las facultades de filosofía y humanidades y ciencias económicas y administrativas de la Universidad de Chile. Rector de la Universidad Andrés Bello. Autor de Lenguaje y experiencia y humana (1980); La libertad politica en el pensamiento de los siglos XVII y XVIII (1987); Para leer la Divina Comedia (2003).

En Estudios Públicos había publicado "Escritos filosóficos políticos de Dante", antología del pensamiento filosófico, jurídico y político del poeta florentino al que dedicó tanta atención. Aquí también publicó selecciones del pensamiento de humanistas italianos del Renacimiento, así como de Erasmo de Rotterdam, Immanuel Kant, Wilhelm von Humboldt y Alexis de Tocqueville.

El Centro de Estudios Públicos tiene el agrado de dar a conocer este ensayo en calidad de obra póstuma de su autor. 
to which rhetoric is philosophy. This article endeavors to describe the facts and acts that Grassi might have used to support this thesis and, at the same time, to clarify its significance.

Keywords: philosphy, rethoric, verisimilitude, humanism, rationalism.

Received: May 2013; accepted: May 2013.

【a retórica goza hoy con frecuencia de un especial desprestigio; y no sin motivo. ¡Cuántas veces no hemos visto utilizar palabras rebuscadas, giros insólitos y toda clase de artificios retóricos sin otra finalidad que la de ocultar la carencia de ideas de un discurso! Así, la que fue el eje de la formación humanista por lo menos hasta el siglo XVIII ha ido perdiendo presencia de manera progresiva y hoy es difícil hallarla mencionada en los programas educacionales de la civilización occidental. Con todo, en 1980 apareció en los Estados Unidos un libro de filosofía titulado La Retórica como filosofía ${ }^{1}$. ¿Su autor? Ernesto Grassi (1902-91), un filósofo italiano que enseñó durante toda su vida en Alemania y también durante un breve período en Chile. ¿Su tesis? Que la retórica es legítimamente una disciplina filosófica de cuyos procedimientos el pensamiento no puede prescindir.

La extrañeza que el mencionado planteamiento de Grassi podría generar en cualquier persona sensata es perfectamente legítima. De hecho, el autor del libro volvió a publicar un capítulo de él en otro contexto, junto con un nuevo ensayo titulado "Por qué la retórica es filosofía" 2 . En él, se basa en la diferencia ontológica de Heidegger, en la tesis sobre el lenguaje del romántico alemán Novalis, en un análisis fenomenológico del juego y en algunos elementos aportados por diferentes autores, principalmente humanistas, para explicar dicho por qué. Por ese motivo, y para no repetir lo ya dicho en el trabajo mencionado, no hemos querido en el presente artículo hacer una simple recensión de la cuestionada obra de Grassi, sino recoger las princi-

${ }^{1}$ Ernesto Grassi, Rhetoric as Philosophy. The Humanistic Tradition, 1980

${ }^{2}$ Ernesto Grassi, Vico and Humanism. Essays on Vico, Heidegger, and Rhetoric, 1990 (traducción castellana, Anthropos, Barcelona, 1999). 
pales fuentes que contribuyeron directa o indirectamente a configurar la noción de retórica concebida por él y explicar así su tesis, extraña tan sólo en apariencia. No se trata de hacer historia de la filosofía ni tampoco historia de un problema filosófico, sino tan sólo de aclarar el sentido que pueda tener la retórica en su conexión con el pensamiento $\mathrm{y}$, en general, con la vida humana en sus diversos aspectos y escenarios de acción.

\section{La sofística y Platón}

La retórica fue entendida tradicionalmente como arte (o técnica) de la persuasión. Como disciplina susceptible de ser enseñada y aprendida, fue creación de los antiguos griegos y fue cultivada principalmente en las ciudades democráticas, donde los ciudadanos estaban permanentemente requeridos para participar y dar su opinión en las asambleas deliberativas llamadas a decidir el destino de la ciudad en la aprobación o rechazo de un proyecto de ley, o en cuestiones de guerra y de paz, de relaciones con otros Estados, de política económica, de observancia religiosa, y otras, para no mencionar los discursos en las importantes ceremonias y solemnidades cívicas que contribuían a inclinar los ánimos de los participantes en conformidad con los intereses de su ciudad. No sólo esto. Esos mismos ciudadanos estaban permanentemente expuestos a comparecer ante tribunales formados por un jurado numeroso de miembros elegidos por sorteo, para responder por acusaciones fundadas o infundadas de corrupción, de malversación de fondos públicos, de amenazar el orden político, de entrar en connivencia con los enemigos, de impiedad hacia los dioses de la ciudad, etcétera. No hay que olvidar que los sicofantes, que vivían de tales acusaciones y de la extorsión a los ciudadanos, amenazándolos con acusarlos y vendiéndoles su silencio, constituían una profesión, si no respetada, por lo menos tolerada en los regímenes democráticos. Frente a las posibles acusaciones ante los tribunales, los ciudadanos debían defenderse ellos mismos, porque no existía formalmente una profesión de abogados a quienes pudiera contratarse para asumir la defensa ajena. Para tener éxito en una u otra de estas circunstancias se necesitaba, obviamente, una destreza en el arte de persuadir a los tribunales o a las asambleas de ciudadanos sobre quienes caía la responsabilidad de adoptar las decisiones. 
Se comprende fácilmente que, en una atmósfera cívica semejante, la sofística desempeñara una función destacada. Hoy goza este movimiento de mala reputación debido a las críticas negativas, filosóficamente justificadas, que recibió de parte de Sócrates, Platón y Aristóteles, pero es necesario considerar que los sofistas fueron personas inteligentes e instruidas que supieron responder en cierta medida a las necesidades sociales de su tiempo. Es verdad que el homo mensura de Protágoras introduce un relativismo que deja a cualquier conocimiento sin asidero; también es verdad que, en su Elogio de Helena, Gorgias defiende lo moralmente indefendible; y asimismo lo es que la tesis de Trasímaco, en el primer libro de La república de Platón, se ajusta a la realidad política contingente pero elimina de raíz toda justicia auténtica posible. Es verdad también que la corrupción, amenazante siempre en los sistemas políticos sin exceptuar a los regímenes democráticos, hizo prevalecer la injusticia y hacer triunfar malas causas, de lo cual la historia de la Grecia antigua ofrece sobrados ejemplos. Pero los sofistas contribuyeron a introducir, por lo menos en Atenas, un movimiento considerable de ilustración, y en este sentido su mérito es indiscutible.

No es, pues, extraño que en esta situación ambigua Platón haya emitido juicios divergentes respecto de la retórica. En su diálogo Gorgias, que no por azar lleva el nombre del célebre sofista, Platón hace que Sócrates niegue, en primer lugar, que la retórica es un arte (techne), es decir, una disciplina, y la rebaja al nivel de una mera empeiría, una destreza práctica que no se funda sobre un auténtico saber y que consiste en un halago o adulación para gratificar a la audiencia. En efecto, el hombre es, según Platón, un compuesto de alma y cuerpo, y estos dos se sirven de dos auténticas artes: el arte política, que está al servicio del alma, y un arte sin nombre que está al servicio del cuerpo; ambas se subdividen a su vez en dos partes, una normativa y una correctiva; la parte normativa de la política es la legislación, y su parte correctiva, la justicia; para el arte que está al servicio del cuerpo, la parte normativa es la gimnástica y la correctiva, la medicina. Tenemos, pues, cuatro artes auténticas que rigen sobre la vida humana: la legislación, la justicia, la gimnástica y la medicina. Pero a estas cuatro artes corresponden cuatro formas no auténticas, espurias, meras simulaciones que no son lo que parecen ser y sólo intentan engañar: ellas son la sofística y la retórica para el alma, la cosmética y la culinaria para el cuerpo. Éstas no son propiamente artes (technai) sino meras prácticas, porque no pueden 
dar razón de su propia existencia. La simulación de la legislación es la sofística, la de la justicia es la retórica, la de la gimnástica, la cosmética y la de la medicina, la culinaria (Gorgias, 462 b - 465 e). En suma, la retórica es a la auténtica justicia como la culinaria a la medicina; la culinaria halaga al paladar preparando alimentos sabrosos sin preocuparse por su valor nutritivo ni por la salud del cuerpo; de análoga manera, la retórica halaga a los auditores sin preocuparse por la justicia y equidad de sus planteamientos.

Frente a la negatividad de esta comparación de la retórica con la cocinería, y en oposición a ella, encontramos en el mismo diálogo platónico una concepción completamente positiva de lo que la retórica debería ser pero, por desgracia, no era en la mayoría de los casos. Platón distingue entre la retórica habitual, mera adulación y halago, y "otra noble que mira hacia el mejoramiento de las almas de los ciudadanos y procura decir lo que es mejor, guste o no guste a la audiencia" (Gorgias, 503 a). Y agrega: “¿No tendrá el auténtico orador retórico, que es honesto y entiende bien su arte, la vista fija en la templanza y la justicia en todas las palabras que dirige a las almas de los hombres y en todas sus acciones, tanto en lo que entrega como en lo que quita? ¿No será su objetivo implantar la justicia en las almas de los ciudadanos y eliminar en ellas la injusticia, implantar la templanza y eliminar el desenfreno, implantar todas las virtudes y eliminar los vicios?" (504 d-e). Quedan caracterizados así la "buena retórica" y el rhetor technikòs kaì agathós ("el orador bueno y conocedor de su oficio") que más tarde será el vir bonus dicendi peritus ("el hombre bueno y experto en el arte de hablar") de Quintiliano. Las referencias a esta "buena retórica" en el Gorgias son meras alusiones, pero en otro de sus diálogos, el Fedro, probablemente posterior a aquél, Platón contrapone, con el despliegue de ejemplos concretos, la vana retórica de los sofistas y una retórica auténtica que mira a la persuasión con vistas al bien y a la justicia. Sin embargo, una sistematización filosófica de la retórica fue una tarea que quedó reservada en gran medida a Aristóteles.

\section{Aristóteles}

A diferencia de Platón, Aristóteles dedicó a la retórica un tratado especial en tres libros. En el comienzo mismo de la obra afirma que "la retórica es una contraparte (antistrophos) de la dialéctica" (Retó- 
rica, 1354 a 1). La "dialéctica" no es para él lo mismo que para Platón; mientras para éste es el movimiento del pensar riguroso que asciende desde lo más elemental hasta las supremas verdades necesarias y universales, para Aristóteles la dialéctica es una forma de argumentación no apodíctica, es decir, que no posee el rigor propio de la ciencia, pero que tampoco es falsa ni contenciosa y no se limita a tener la sola apariencia de verdad, y que se funda en opiniones comúnmente aceptadas. A pesar de que esta concepción de la dialéctica hace de ella una disciplina menos rigurosa de lo que estimaba Platón, la retórica y la dialéctica son para Aristóteles, contrariando la primera valoración de la retórica hecha por su maestro, artes (technai) y no meras prácticas. Para apoyar su nueva tesis, aduce Aristóteles que la retórica posee procedimientos de prueba que le son propios, y critica de paso a los autores de manuales en circulación en su tiempo, que nada decían acerca de las pruebas retóricas, limitándose a ofrecer recetas para obtener el dudoso efecto de excitar las pasiones de los jueces, con lo cual hacían posible pervertir la verdad o la justicia.

¿Qué quiso Aristóteles dar a entender con su afirmación de que la retórica es antístrophos o contraparte de la dialéctica? Hallamos nuevamente este término en el lenguaje de la técnica dramática de la tragedia, donde la antistrophé es una parte del recitado del coro que posee la misma estructura métrica de la strophé, de la estrofa, pero expresa naturalmente otra idea. Mi sospecha es, por tanto, que Aristóteles quiso afirmar que la retórica posee la misma estructura, no métrica, por cierto, sino argumental, que la dialéctica, pero con otros contenidos. Esto adquiere mayor evidencia cuando se examina el problema de las pruebas retóricas.

Aristóteles se enorgullecía de ser el primer tratadista que investigó las pruebas retóricas. Las dos más importantes son a su juicio el entimema y la ejemplificación (parádeigma). "La ejemplificación" nos dice "es una inducción (epagogé) y el entimema es un silogismo; bien puede afirmarse, entonces, que el entimema es el silogismo retórico y la ejemplificación, la inducción retórica" (1356 b 3-5). Recordemos aquí que la epagogé, traducida habitualmente como inducción, no se confunde de ninguna manera con el concepto moderno de inducción. Esta última consiste, en efecto, en la reunión del mayor número posible de casos particulares para obtener, a partir de ellos, un enunciado de carácter general. Para los antiguos griegos, empero, los enunciados universales 
no se obtienen por medio de una acumulación mecánica de datos particulares sino que tienen su origen en una operación directa del logos (el entendimiento) en cuanto centro de las fuerzas espirituales del hombre. La proposición universal no es entonces el producto sino el supuesto previo de la epagogé. Ésta consiste en exhibir algunos casos particulares - tal vez uno solo, si ello es suficiente - trayéndolos a la discusión como "testigos" capaces de confirmar la validez del enunciado general.

Del entimema nos dice Aristóteles que es un silogismo. El entimema aristotélico no es un silogismo abreviado o un silogismo con una premisa tácita, como suelen definirlo los manuales modernos de lógica. Para el estagirita, dicho rasgo no es esencial ni definitorio. Un silogismo es para él un razonamiento en que, dadas al menos dos proposiciones, se infiere de ellas una tercera; al menos una de las dos premisas del silogismo debe expresar un enunciado universal. Propio del entimema es, pues, obtener una conclusión a partir de ciertas premisas, y contener entre éstas al menos un universal de carácter retórico. En otra de sus obras define Aristóteles al entimema como "un silogismo desde verosimilitudes o signos" (Primeros analíticos, 70 a 10). El universal retórico no es lógicamente necesario, como el universal apodíctico propio de las inferencias científicas; no es preciso, tampoco, que sea aceptado al menos por los hombres más sabios, como el universal dialéctico; tampoco es una premisa sólo aparentemente aceptada, como el universal erístico. El universal retórico es verosímil, tan sólo semejante a la verdad. Se asemeja a la verdad porque tiene el carácter de universalidad, pero no se identifica con ella porque no posee el carácter de necesidad propio del universal apodíctico. Lo que vale para el universal retórico vale también para las conclusiones de los entimemas. Son conclusiones que se encuentran, por así decirlo, en un punto intermedio entre las "verdades puras" de la ciencia y las "falsedades puras" del error y del engaño. No podemos decir que los enunciados obtenidos por la retórica son falsos de suyo, puesto que puede ocurrir que sean verdaderos, y muy verdaderos; más bien podemos considerarlos como verdades no suficientemente garantizadas, que en su mayor parte son verdaderas (son, después de todo, opiniones comúnmente aceptadas) aunque algunas de ellas puedan resultar falsas después de un examen riguroso. En cualquier caso, lo importante aquí es retener que mientras el silogismo científico posee el carácter de la necesidad lógica, el silogismo retórico o entimema es solamente verosímil, no necesario. 


\section{El significado filosófico de la retórica en la Antigüedad}

En la práctica, la sofística griega había vinculado estrechamente a la retórica con la política y había hecho del arte de la persuasión un instrumento de las luchas por el poder en que suelen degenerar las actividades políticas. La retórica se revelaba así como el arma que permitía imponer la adopción por los ciudadanos de decisiones favorables a los intereses del orador o de sus patronos.

Hemos visto ya cómo la concepción de una "buena retórica" sugerida por Platón intentaba superar y eliminar esa particular perversión. También para Aristóteles, quien se mantuvo en este punto fiel al pensamiento de su maestro, la ley (entendida idealmente como expresión de la justicia) debe prevalecer sobre la persuasión retórica, de manera que a esta última le corresponde un lugar secundario y limitado dentro de la vida cívica. La función de la retórica es para él tan sólo facilitar el juicio correcto acerca de los casos particulares. En efecto, la ley posee necesariamente carácter general y no puede ponerse en todos los casos particulares posibles. La retórica tiene que mostrar el camino que permita la aplicación correcta, acertada y justa de la ley a cada caso concreto. Ella queda, de esta manera, puesta al servicio de lo verdadero y de lo justo.

De aquí resulta una consecuencia muy importante para la adecuada concepción de la retórica. Parece evidente que la persuasión también puede ser utilizada para inducir a hacer el mal. Por consiguiente, la función y la utilidad de la retórica no puede ser la de persuadir, sino tan sólo la de hallar en cada caso los medios posibles de persuasión. La distinción parece muy sutil, y por eso Aristóteles procura aclararla mediante un ejemplo. Si dijéramos que la función de la medicina es restablecer la salud, rápidamente nos hallaríamos frente al problema de los enfermos incurables; puesto que en ellos la salud no puede restablecerse, la medicina no tendría ninguna función que cumplir en su caso y tales enfermos no deberían ser tratados. Pero la función de la medicina no es restablecer la salud sino encontrar los medios para ello; por tanto, a los enfermos incurables se les puede administrar dichos medios sin entrar a considerar si en su caso la salud es alcanzable o no lo es. Análogamente, la retórica buscará los medios para persuadir acerca de esto o de lo otro sin hacer de la persuasión misma su objeto propio (Retórica 1355 b 7 ss.) 
La función de la retórica así entendida permite comprender el significado de la afirmación aristotélica según la cual "la retórica es una ramificación (paraphyés) de la dialéctica y de la ética" (1356 a 25). No sólo posee la retórica, como hemos visto, una estructura del procedimiento argumentativo y probatorio similar al de la dialéctica, sino que, además, se presenta como una ramificación de ella. La retórica constituye el camino que permite transitar entre lo universal y lo particular. En una asamblea deliberativa, por ejemplo, ella permite establecer la existencia o inexistencia de una correspondencia entre los intereses superiores y universales de la ciudad y la decisión concreta que se propone adoptar. Más claramente se percibe esta relación en los procesos judiciales. Consideremos como un ejemplo el caso concreto del asesinato de Julio César. El homicidio había sido perpetrado en presencia de todo el Senado romano; todos los senadores vieron quiénes fueron los hechores, cuándo, dónde, cómo y en qué circunstancias cometieron el asesinato. Pero no todos habrían sabido decir si se trataba de un magnicidio (o parricidio, para respetar la terminología jurídica romana) o de un tiranicidio. El problema no era menor; si era parricidio, los asesinos debían ser castigados con toda la severidad de la ley; pero si era más bien tiranicidio, los asesinos se hacían acreedores al respeto, a la admiración y eventualmente a una recompensa por parte de la ciudadanía. En circunstancias normales, el asesinato debería haber sido juzgado por el Senado; pero las circunstancias políticas de la Roma de la época distaban mucho de ser normales: ante el hecho, los senadores huyeron despavoridos y todo terminó en una guerra civil en que la victoria fue de los partidarios del proyecto político de César. Pero es claro que el desenlace de una guerra civil no avala la legalidad o ilegalidad ni la moralidad o inmoralidad de un hecho. Nada puede sustituir en este caso a una sentencia fundada emitida por un tribunal informado y ecuánime. Por eso, si hubiera tenido lugar un juicio - que no lo hubo-, acusadores y defensores habrían debatido acerca de si el homicidio en cuestión, un hecho concreto particular, debía ser considerado como un caso más de los conceptos generales de parricidio o de tiranicidio. Para ambas tesis los litigantes habrían encontrado numerosas razones que las fundaban, como puede atestiguarlo la historia del correspondiente período de la república romana y de sus principales actores. Y en lugar de las armas bélicas utilizadas en la guerra civil, acusadores y defensores sólo habrían contado con las armas de la retórica empleada en sus discursos 
forenses para apoyar sus respectivas posiciones. La relevancia de la retórica queda, a nuestro juicio, claramente de manifiesto en este ejemplo.

La retórica facilita el juicio correcto acerca de los casos particulares estableciendo el vínculo entre ellos y un determinado universal. De esta manera, ayuda a que la decisión acerca de lo particular sea justa, es decir, se "ajuste" a la justicia expresada por un enunciado universal. La retórica tiende así un puente entre lo universal y lo particular; desde este punto de vista podría decirse que ella constituye el medio por el cual el hombre logra hacer efectiva la méthexis, la "participación" platónica de lo particular en lo universal, en el terreno de las decisiones y de las acciones humanas. Este carácter se hace presente en todos los ámbitos, incluso y principalmente en aquellos en que la razón lógica tiene una contribución mínima o nula. En la reflexión ética de Aristóteles encontramos también la aplicación de esta perspectiva respecto del tema de la justicia y la equidad: "[...] toda ley es general, pero tocante a ciertos casos no es posible promulgar correctamente una disposición en general. En los casos, pues, en que de necesidad se ha de hablar en general, por más que no sea posible hacerlo correctamente, la ley toma en consideración lo que más ordinariamente acaece, sin desconocer por ello la posibilidad de error. Y no por ello es menos recta, porque el error no está en la ley ni en el legislador, sino en la naturaleza del hecho concreto, porque tal es, directamente, la materia de las cosas prácticas. En consecuencia, cuando la ley hablare en general y sucediere algo en una circunstancia fuera de lo general, se procederá rectamente corrigiendo la omisión en aquella parte en que el legislador falló y erró por haber hablado en términos absolutos, porque si el legislador mismo estuviera ahí presente, así lo habría declarado, y de haberlo sabido, así lo habría legislado" (Ética Nicomáquea, 1137 b 13 ss.)

El modo en que lo particular puede estar contenido en lo universal —o, lo que viene a ser lo mismo, el modo en que lo sensible puede corresponder a lo inteligible - constituye un problema que mantuvo siempre en perplejidad al pensamiento griego. Esta dificultad es aún más evidente en el ámbito de la acción humana. Las acciones y decisiones humanas son siempre individuales y cognoscibles mediante uno o más de los sentidos. Lo individual posee carácter concreto; lo universal — la ley, la norma, el modelo, la "idea" platónica, el género inteligible - tiene carácter abstracto y es conocido sólo por el intelecto. ¿Cómo puede, entonces, lo abstracto contener a lo concreto, o lo 
concreto "realizar" lo abstracto? ¿Cómo puede una acción individual ser, por ejemplo, justa, esto es, modelarse según la noción universal abstracta de justicia? ¿Cuál es el vínculo que une a objetos tan radicalmente disímiles? El problema se complica al considerar que, desde Platón y Aristóteles, nos hemos habituado a pensar que el "saber más" y el saber en mayor profundidad es siempre saber de lo universal alejado de la realidad particular concreta. Y es claro que el único camino para efectuar el tránsito entre uno y otro nivel —el de lo individual concreto y el de lo universal abstracto- es hecho posible por el lenguaje en su dimensión propiamente retórica. Éste cierra el círculo de la reflexión vinculando lo particular con lo universal, lo contingente con lo necesario, lo concreto con lo abstracto.

El hombre, según la concepción tradicional, posee dos facultades diferentes, la sensibilidad y la intelección, para tomar contacto con los dos ámbitos análogamente diferentes de la realidad: lo individual, lo concreto y lo puramente sensible por un lado, y lo universal, lo abstracto y lo puramente inteligible por el otro. La Edad Media consideró que este hecho constituye una insuficiencia del saber humano y llegó a pensar que los ángeles (concebidos siempre como seres espirituales superiores al hombre pero que sólo pueden ser representados bajo formas humanas) poseen un conocimiento cuya superioridad sobre el conocimiento humano consiste principalmente en que aprehenden lo individual y lo universal, lo material y lo espiritual en un solo acto y mediante una sola facultad intelectiva ${ }^{3}$.

Se hace claro también aquí que la retórica aparezca como una "ramificación" de la ética. Ello no obedece primaria ni únicamente a que la retórica pueda ser usada tanto para inducir a hacer el bien como a hacer el mal, sino ante todo a que ella permite satisfacer el imperativo ético de configurar la acción humana, que es siempre particular en cada caso, de acuerdo con principios universales. Y no es extraño que sea precisamente la retórica, en cuanto disciplina de la palabra, la llamada a cumplir esta función; recordemos tan sólo que, para Aristóteles, la ética forma parte de la política y esta última se constituye en virtud de la facultad de la palabra que sólo el hombre posee. El rasgo deliberativo, que caracteriza no sólo a la retórica de las asambleas sino también a la retórica forense y (tal vez en menor medida) a la retórica epidíctica (la

${ }^{3}$ Sto. Tomás de Aquino, S. Theol., I, q. 57, ad 2. 
de las ceremonias y celebraciones), es propio de toda retórica en la medida en que ella se ofrezca en el ámbito de lo contingente, ya que nadie delibera acerca de lo que es lógica o empíricamente necesario. Pero si la deliberación más noble es la que se refiere a lo futuro, a lo que deberá ocurrir, resulta que la retórica dice relación con la acción humana en el ejercicio efectivo de su libertad. La retórica es una disciplina de la libertad porque las acciones humanas libres son contingentes y revelan cambios y modificaciones a través del tiempo. En suma, si la vida humana es propiamente vida en comunidad, la retórica es el instrumento que permite realizarla plenamente en su forma más alta y más digna.

\section{Cicerón y Quintiliano}

$\mathrm{Al}$ comienzo de una de las obras de juventud de Cicerón, el tratado De inventione ("Sobre el hallazgo"; la inventio es precisamente la parte de la retórica que tiene por tema el hallazgo de los argumentos que permiten defender una tesis), se remite Cicerón a una suerte de "estado de naturaleza" de la humanidad primitiva al que pone fin la fuerza de la elocuencia acompañada de sabiduría. En los primeros capítulos, que se transformaron en un locus classicus para los autores más tardíos, se refiere a los hombres que inicialmente vagaban por los campos como animales, motivados únicamente por sus pasiones y confiados en sus solas fuerzas físicas, sin religión, sin deberes hacia los demás, sin matrimonios, sin una justicia ecuánime que resolviera los conflictos entre ellos. Fue entonces, dice, algún hombre sabio y superior quien, reconociendo las posibilidades propias del alma humana y su capacidad de mejoramiento, logró, gracias a su elocuencia, persuadir a los demás para que se agruparan, erigieran ciudades, respetaran la justicia, obedecieran a sus autoridades y colaboraran en las tareas conducentes al bien común. Aquel hombre debió reunir en sí la fuerza de la elocuencia y la penetración de la sabiduría para poder lograr su objetivo, porque "la sabiduría sin elocuencia ha sido de poco provecho para los Estados, pero la elocuencia sin sabiduría ha sido a menudo un gran obstáculo y nunca una ventaja para ellos" (De inv., I, 1-2).

Esta idea inicial de la unión de sabiduría y elocuencia fue conservada y desarrollada por Cicerón en los escritos de su edad madura. En el De oratore nos habla de lo que los antiguos llamaron sabiduría ( $s a-$ 
pientia), a la que define como un modo de pensar y de hablar (cogitandi pronuntiandique ratio): "antiguamente la misma disciplina enseñaba a actuar bien y a hablar bien, y no había maestros diferentes que enseñaran a vivir y a hablar" (De orat., III, 15). Algunos hombres eminentes, sin embargo, que se alejaron de la vida política y de los negocios, llegaron a despreciar la práctica de la elocuencia para concentrarse únicamente en el saber, no en el hablar. El más importante de ellos fue Sócrates, quien, con el prestigio de su sabiduría, sirvió de ejemplo para la desvalorización de la elocuencia. Sócrates fue así responsable de haber separado dos cosas originariamente unidas, la ciencia de pensar sabiamente y la de expresarse bella y elegantemente. Él originó el divorcio absurdo, inútil y reprochable del corazón y la lengua (III, 16). "Los antiguos, hasta Sócrates, unían al arte de la palabra todo el saber referente a las costumbres de los hombres, a su vida, a la virtud y al Estado; separados después los elocuentes y los doctos por Sócrates [...], seguido en ello por todos los socráticos, los filósofos despreciaron la elocuencia y los oradores la sabiduría" (III, 19). Se abrió así el camino para una retórica que atiende únicamente a la belleza y eficacia del lenguaje, pero no al pensamiento, y que acaba en una elocuencia artificiosa y superficial destinada a encubrir la carencia de ideas de un discurso.

Tanto Cicerón como más tarde Quintiliano, el sistematizador de la retórica antigua, insistieron en la necesidad de que, para ser eficaz, el discurso retórico debía ser adornado con ciertos tropos, de los cuales el más importante es la metáfora. Reconocieron que la metáfora no es tan sólo un ornamento prescindible en el discurso, sino que es necesaria para que ningún objeto o circunstancia quede sin denominación y, sobre todo, para que, al aumentar el número de objetos a los que se atribuye un significado similar, se extiende también el mundo de las significaciones posibles, es decir, el mundo de nuestras experiencias. Hay una semejanza, dice Cicerón, entre la metáfora y la vestimenta; esta última fue inventada primero por la necesidad de defenderse del frío, pero luego se desarrolló de tal modo que sirviera como ornato del cuerpo y expresión de la dignidad de la persona que la lleva. Lo mismo ocurre con el lenguaje apropiadamente utilizado. Desde la necesidad primaria de la comunicación, el lenguaje se ha desarrollado hasta constituir un ornato que atrae y domina por su belleza y elegancia.

La lectura de lo dicho por Cicerón y Quintiliano sobre la metáfora, que no consideraremos aquí en su integridad, deja en claro, 
por otra parte, que para ellos el uso de este tropo es un modo del aletheúein, del develar aspectos antes ocultos del ser de lo ente; es decir, la metáfora posee una función netamente metafísica, pone de manifiesto nuevos aspectos del ser de las cosas y no se limita a ser un mero ornato exterior del discurso. En efecto, la metáfora puede surgir tan sólo, como ya lo había señalado Aristóteles, de una visión de las semejanzas entre las cosas, visión que es obra de la facultad del ingenio (el ingenium, la euphyía o disposición natural aristotélica), que tendrá enorme importancia en la tradición no racionalista del problema del saber.

\section{René Descartes}

Descartes es sobradamente conocido y reconocido como "padre de la filosofía moderna". Para entender adecuadamente, sin embargo, la relación de Grassi con el cartesianismo es bueno considerar la doble apreciación en que tuvo al pensamiento de Descartes. En efecto, celebró con entusiasmo, por una parte, el hallazgo del principio del cogito (i.e. del "pienso") y lo interpretó — acaso bajo la influencia de Giovanni Gentile - no como un objeto, como un "pienso" ya pensado y un pensamiento rígido ya dado, sino más bien como un pensar pensante, un proceso que se autoactualiza permanentemente a cada instante. "El dato, en cuanto 'hecho' ya realizado, es siempre algo completo y no contiene jamás la presencia inmediata que debería ser justamente su verdad. El hecho es la negación del presente [...] El presente inmediato no está contenido en el hecho precisamente porque un hecho, en su interpretación empírica, es algo que ya ha devenido, ya ha sido realizado, mientras debería estar actualmente presente en su verdad. Sólo lo que deviene, lo que no ha devenido aún, lo que no es un hecho, es el presente, lo 'verdadero inmediato' que se evade de toda interpretación empírico-naturalista de la realidad [...] La esencia de la presencialidad inmediata - que debería ser la esencia del develar empírico- no es, pues, lo que ha devenido y ha cristalizado como hecho, como objeto, sino más bien el devenir mismo, el manifestarse [...] Si la concepción objetivista de lo verdadero excluye la presencia inmediata que debería ser su esencia, el manifestarse de algo no puede ser entendido sino como un proceso de automanifestación"4. Esta interpretación le permitió a Grassi

\footnotetext{
${ }^{4}$ Ernesto Grassi, "Il Problema del Logo" [1936], 2011, pp. 374-5.
} 
evitar los escollos de un objetivismo y de un idealismo racionalistas en la interpretación de la duda metódica y del cogito cartesianos.

Si bien es verdad que esta interpretación de Descartes puede aplicarse legítimamente tan sólo a las dos primeras de sus Meditaciones metafisicas, porque ya a partir de la tercera meditación recurre nuevamente el filósofo a la noción tradicional y trascendente del ser, Grassi pudo hacer uso de su nuevo esfuerzo interpretativo del cogito como justificación de la opinión habitual que ve en Descartes al "padre de la filosofía moderna" y al precursor del idealismo moderno. Es perfectamente posible, con todo, que Descartes no se reconociera a sí mismo en la interpretación que de él hace Grassi, pero ello tuvo a este último muy sin cuidado, pues si se acercaba a los clásicos de la filosofía, no era para establecer con criterios historiográficos la validez de sus doctrinas, sino para hallar en sus escritos sugerencias desencadenantes de nuevos desarrollos teoréticos. Éste fue, al igual que para su maestro Heidegger, el principio fundamental de la hermenéutica filosófica de Grassi.

En un trabajo posterior al ya citado, reitera Grassi su interpretación propia del cogito, según la cual —al contrario de la interpretación tradicional, en que la investigación del fundamento del saber se realiza como búsqueda de objetos racionales claros y distintos-, "el cogito en tanto que fundamento del saber (y por tanto también la 'claridad' y 'distinción' que se le atribuyen) no es el cogito en tanto que objeto racional [...] de una visión fenomenológica”, de modo tal que su verdad "no resulta cuando se le hace objeto de un análisis [...], sino que sólo demuestra ser el fundamento del saber al realizarse a sí misma"s.

No obstante lo dicho anteriormente, otro aspecto del pensamiento cartesiano, a saber, su actitud abiertamente contraria a la retórica, mereció en el mismo artículo citado el enfático rechazo por parte de Grassi, quien hizo suya en este respecto la argumentación anticartesiana de Vico a la que nos referiremos en el próximo apartado. Dice Descartes: "Yo estimaba mucho la elocuencia y estaba enamorado de la poesía; pero pensaba que la una y la otra eran dones del espíritu más bien que frutos del estudio. Quienes poseen el razonamiento más fuerte y dirigen mejor sus pensamientos para hacerlos claros e inteligibles, siempre pueden persuadir mejor acerca de lo que proponen aunque no hablen más que p. 498.

5 Ernesto Grassi, "Der Begin des modernen Denkens” [1940], 2011, 
bajo bretón y jamás hayan aprendido retórica" (Disc. de la méthode, $1^{\mathrm{a}}$ parte). La retórica queda así valorizada negativamente. En el próximo apartado consideraremos las objeciones que hizo Vico a la duda metódica cartesiana. Allí comprobaremos que la actitud antirretórica de Descartes desvaloriza también por completo a la vida política, a la vida religiosa, a la creación artística y, en general, a la vida cotidiana.

En efecto, la existencia humana, que ha perdido en medida importante la seguridad y certeza ofrecidas por la vida animal instintiva, necesita orientarse y guiarse por principios de conducta que le permitan responder adecuadamente a los estímulos provenientes del mundo exterior. Dichos principios pueden — no necesariamente - recibir la forma de un enunciado comunicable en que se especifica la naturaleza del estímulo y la de la correspondiente respuesta. Así surgen las diferentes "éticas" que pueden exhibir los agentes: ética del placer, ética de la virtud, ética del deber, ética del humanitarismo, ética de la utilidad, etcétera, según cuál sea el estímulo motivador de la acción. Pero todas estas no sólo se sirven de la retórica para expresarse sino que además carecen generalmente de la necesidad lógica que confiere universalidad a sus principios. La negación cartesiana del valor de la retórica va a alcanzar también a los entimemas retóricos y, con ellos, al acceso hacia los principios éticos, políticos, religiosos y estéticos.

\section{Giambattista Vico}

En el año 1709 publicó Vico su De nostri temporis studiorum ratione ("Sobre el método y programa de los estudios en nuestro tiempo"), reelaboración de un discurso inaugural pronunciado por él en la Universidad de Nápoles, donde era profesor de retórica. La obra comienza anunciando su propósito: “¿Cuál de los dos métodos de estudios es más correcto y mejor, el nuestro acaso o el de los antiguos? A lo largo de esta disertación confrontaremos [...] las ventajas y desventajas de entrambos $[\ldots]^{\prime \prime 6}$. Parece, a primera vista, que se trataría de una intervención más, como muchas otras, en la querelle des anciens et des modernes desencadenada en el siglo anterior por Perrault y extendida rápidamente por toda Europa. Pero la disertación va mucho más allá: contiene una crítica radical del cartesianismo dominante en la organiza-

${ }^{6}$ Giambattista Vico, Obras. Oraciones inaugurales. La antiquísima sabiduria de los italianos, 2002, p. 78. 
ción de los estudios en la época, y el intento de superar las limitaciones de dicho sistema incorporando en los programas algunas perspectivas que habían sido cultivadas en la Antigüedad pero que tendían a caer en el olvido en el siglo XVIII.

Al sistema cartesiano, en conjunto con el atomismo de Gassendi y la lógica de Port-Royal, los llama Vico "pensamiento crítico" o simplemente "crítica". Reconoce que dicho sistema ha hecho posible el logro de progresos enormes en las ciencias y en las técnicas, pero al mismo tiempo señala sus limitaciones. La crítica tiene por finalidad última exclusivamente el hallazgo de la verdad; para ello, parte de la duda metódica que permite encontrar la verdad indubitable del cogito, ergo sum; pero la duda metódica exige también poner en duda y considerar falsos todos los conocimientos que no sean el del cogito mismo o los que de él derivan lógicamente. Esto supone considerar falsas todas las afirmaciones verosímiles que sirven de premisas a los entimemas retóricos. Con ello, se desvaloriza por completo a la elocuencia y a su función en la vida civil, en la política, en la religión y en la vida cotidiana.

En efecto, de las verosimilitudes nace el sentido común, al que Vico define en la Ciencia nueva como "un juicio sin reflexión alguna, experimentado universalmente por todo un grupo, por todo un pueblo, por toda una nación o por todo el género humano" ( $\S \S 141-42)$. No la verdad de la crítica, sino el sentido común, hecho de meras verosimilitudes, es la regla de toda prudencia (en el sentido de la phrónesis, el saber moral) y de la elocuencia, que a su vez se vinculan con las necesidades y la utilidad humanas; necesidades y utilidad que no son inamovibles, como la verdad inconcusa de la crítica, sino que cambian y varían dependiendo de las circunstancias históricas y de las inciertas decisiones adoptadas por los hombres en el ejercicio de su libertad. La insistencia en la crítica y la falta de adiestramiento de los jóvenes en las cosas relativas al sentido común, dice Vico, es causa de que ellos no desarrollen su memoria y su fantasía, y lleguen faltos de liderazgo, madurez y prudencia al manejo de los asuntos públicos.

Al método crítico de los modernos opone Vico el método "tópico" de los antiguos. En la Ciencia nueva describe a la tópica como "el arte de regular bien la primera operación de nuestra mente, enseñando cuáles son todos los lugares (tópoi, loci) que se deben recorrer [mentalmente] para conocer todo cuanto hay en las cosas que se quiere conocer bien o completamente" (§ 497); y agrega que "la providencia dispuso 
bien las cosas humanas al promover en las mentes de los hombres la tópica antes que la crítica, puesto que primero se conocen las cosas, después se las juzga. Porque la tópica es la facultad de hacer las mentes ingeniosas, así como la crítica es la de hacerlas exactas; y en los primeros tiempos había que hallar todas las cosas necesarias para la vida humana, y el hallazgo es propiedad del ingenio [...] Así los primeros pueblos, que fueron los niños del género humano, fundaron primero el mundo de las artes; después los filósofos, que vinieron mucho tiempo después y que son en consecuencia los viejos de los pueblos, fundaron el de las ciencias" (§ 498).

Hay, pues, una precedencia de la tópica sobre la crítica; ello no impide a Vico, sin embargo, reconocer que ambos métodos, el crítico y el tópico, están viciados; el tópico lo está porque, al apoyarse en lo verosímil, con frecuencia adopta significados falsos; el crítico, porque no considera lo verosímil y le quedan extraños los ámbitos de la libertad humana, de la historia, de la moral y del derecho. La solución que ofrece Vico es enseñar a los jóvenes primero la tópica, para desarrollar su fantasía, y sólo después la crítica, para fortalecer su facultad racional.

En la Ciencia nueva describe Vico lo que debe haber sido el desarrollo de la humanidad y de su saber desde la época de los hombres primitivos, fuertes y únicamente sensoriales, dotados por consiguiente de una poderosa fantasía y carentes de raciocinio y de conceptos abstractos, hasta el hombre moderno físicamente más débil, de fantasía embotada pero capaz de razonar con conceptos que alcanzan un alto grado de abstracción. Como los niños, los hombres construyeron primitivamente su saber con la sola fuerza de su fantasía, para lograr poco a poco, a través del tiempo, el dominio progresivo del pensamiento racional. Por eso, la educación de los niños debe comenzar con el cultivo de la fantasía alimentada por imágenes sensibles y conducir paulatinamente hacia el cultivo de la razón y sus abstracciones. La misma Ciencia nueva explica cuál fue el elemento que permitió una transición tan fundamental: los "géneros fantásticos", imágenes (no conceptos) cuyas características se ven como determinantes para objetos diversos: "Los primeros hombres, como niños del género humano, siendo incapaces de formar los géneros inteligibles de las cosas, tuvieron una necesidad natural de fingir los caracteres poéticos, que son géneros o universales fantásticos, para reducir a ellos, como a modelos ciertos o retratos ideales, todas las sabidurías particulares a sus géneros semejantes" 
(§ 209); donde, por ejemplo, “el verdadero capitán de guerra es [...] el Godofredo que imagina Torquato Tasso, y todos los capitanes que no se conforman en todo y por todo a Godofredo, no son verdaderos capitanes de guerra" (§ 205). Los géneros fantásticos de Vico forman así una suerte de puente que vincula a las imágenes sensibles particulares de la memoria y la fantasía de los niños y de los primeros hombres con los conceptos universales abstractos de la razón de los adultos y de los hombres modernos.

Primacía histórica y metafísica de la imagen y la fantasía sobre el concepto y la razón lógica; carácter imprescindible de lo verosímil retórico para la vida cotidiana, moral y política; flexibilidad de las nociones originadas en el sentido común, que es la fuente de la moral y del derecho, frente a la rigidez de los conceptos propios de la razón lógica; éstas son, diría yo, ideas fundamentales elaboradas por Grassi bajo la inspiración del pensamiento de Vico, y con las cuales pudo construir su propio pensamiento a través de los años.

\section{Ernesto Grassi}

En las publicaciones de Grassi, ya antes de una ocupación explícita con el problema de la retórica, aparece el interés por el lenguaje metafórico y su determinación como una modalidad necesaria, imprescindible y fecunda de la expresión lingüística, aun más, como expresión del orden propiamente humano en oposición al orden natural ${ }^{7}$. Igualmente temprano fue su interés por el pensamiento de Vico. Grassi hizo suya la distinción viquiana entre la crítica y la tópica y vio en ella no tan sólo un recurso didáctico para una exposición más clara sino la identificación fundamental de dos modalidades contrapuestas del pensamiento humano y sus respectivos lenguajes. Naturalmente, hubo cambios en la terminología. Al pensamiento y lenguaje "crítico" de Vico llamó Grassi pensamiento y lenguaje racional o científico-demostrativo, y a la "tópica" de Vico se refirió como un lenguaje imaginativo (i.e. no racional), indicativo o semántico (i.e. no demostrativo sino ostensivo), arcaico (i.e. propio de los principios, archaí en griego) e ingenioso (por

${ }^{7}$ Cfr, por ejemplo Ernesto Grassi, Die Macht der Phantasie, 1979, pp. 62 ss. (hay traducción castellana: El poder de la fantasía, Barcelona, Anthropos, 2003) y Macht des Bildes: Ohnmacht der rationalen Sprache, 1970, pp. 169 ss. 
“ingenio" se entendía principalmente en la época de Vico la capacidad de percibir las semejanzas entre las cosas, fundamento de la metáfora).

La esencia del lenguaje racional es para Grassi la demostración, cuyo paradigma o modelo esquemático es el silogismo. Éste consiste en dos o más premisas de las cuales, aplicando ciertas reglas, es posible extraer una conclusión; ésta representa un enunciado nuevo cuya validez depende, como de su principio, de la validez de las premisas correspondientes. El sistema cartesiano se perfila así como una cadena de silogismos que parte de un principio primero ("pienso, luego existo"), de modo tal que las conclusiones obtenidas sirven de premisas para demostraciones ulteriores. Pero los principios de un sistema formalizado son el fundamento de toda demostración, y por ello no pueden ser ellos mismos demostrados dentro del sistema sin entrar en un círculo vicioso. En consecuencia, el primer principio, sobre el cual se fundan todas las demostraciones, carece de demostración.

Aquí se plantea ya el problema de la objetividad en la búsqueda de la verdad. ¿Cómo puede alcanzarse la certeza de que el primer principio, del cual van a depender todos los restantes y que no puede ser demostrado, es verdadero y no falso? Para Grassi, dicha certeza obviamente no puede ser asegurada por los sentidos ni, como hemos visto, demostrada por la razón. Pero un auténtico principio tiene la propiedad de que no podemos sustraernos a él. Así, la negación del principio de no contradicción implica su propia negación, y la negación del principio cartesiano del cogito implica un acto de pensamiento, de cogitatio. El problema está, entonces, en la capacidad no racional de "ver" o concebir el principio, acto que no es propio de la razón lógica sino de una facultad no demostrativa que simplemente lo muestra, y a la que los antiguos griegos llamaron el nô̂s. En cambio, a la capacidad de deducir a partir de los principios, la llamaron los griegos "ciencia" (episteme), sin confundirla con la anterior.

Así, pues, la demostración racional depende de principios que no poseen origen racional. Si bien Grassi no lo menciona, algo análogo ocurre en un sistema lógico formalizado con los conceptos del sistema. Éstos deben ser definidos, pero la posibilidad de hacerlo está fundada en la admisión de algunos conceptos básicos no definidos ni definibles. En pocas palabras: la demostración racional se funda paradójicamente en lo no demostrable y la definición de los conceptos racionales arranca de lo indefinible. Podemos decir entonces que el fundamento de los 
procesos racionales permanece inaccesible para la facultad de la razón. Por eso, Newton pudo explicar los fenómenos físicos de la gravedad y del movimiento de los astros invocando la noción de fuerzas naturales, pero confesó ignorar cuál es la naturaleza de una fuerza: hypotheses non fingo, "no aventuro explicaciones hipotéticas" son sus palabras.

Nos alejaría de nuestro tema preguntarnos si es lícito restringir la noción moderna de ciencia y hacerla equivalente con la noción griega de la episteme. También hay que tener en consideración que cuando Grassi habla de "razón", piensa principalmente en la razón lógica, es decir, una forma de la razón entre otras posibles. Dejando en suspenso estas cuestiones, queda sin embargo en claro que disponemos de dos modalidades diferentes del pensamiento y del correspondiente lenguaje. Una de ellas busca la verdad y consiste en una cadena de deducciones a partir de un principio primero indubitable. La otra consiste en deducciones que no parten de un principio primero indubitable sino de "visiones" de posibles principios que al fin rematan en enunciados tan sólo verosímiles. Este segundo camino no deja de ser importante; es, en efecto, el que caracteriza a nuestras reflexiones más habituales. "Verosímil" no significa en este contexto "falso"; significa más bien "habitualmente verdadero, rara vez falso, y que no deriva su verdad de un principio primero indubitable". Hay, pues, un pensamiento racional consistente en deducir desde principios primeros indemostrables, y otro pensamiento retórico, no menos riguroso pero fundado en premisas meramente verosímiles. Y, como es fácil de inferir, la gran mayoría de las elucubraciones filosóficas pertenecen a este mundo que se presenta bajo el modo de la verosimilitud.

\section{Una pluralidad de mundos}

La existencia de modalidades diferentes del pensamiento y de sus correspondientes lenguajes significa que el hombre interpreta la realidad de una u otra manera, y así sus lenguajes exhiben e individualizan los diferentes productos de la kosmopoiesis, de la construcción humana de mundos. En lo anterior se ha visto surgir un mundo racional de la ciencia entendida como la episteme griega frente al nô̂s, y otro no racional de las verosimilitudes no siempre verdaderas. Pero este último es sumamente rico y complejo, y pueden identificarse en él varias modalidades diferentes. Señalemos provisoriamente algunas de ellas: 
el mundo de la poesía y de la creación artística en general, el mundo de la moral individual y de la política, el mundo de la vida religiosa y, last but not least, el mundo de la vida cotidiana.

El mundo de la poesía y del arte no es entendido por Grassi como el ámbito de la pura subjetividad. Cierto es que la poesía y el arte no buscan la verdad, como el pensamiento racional, sino que procuran más bien crear mundos posibles. Para plantear el problema del arte Grassi recurre al diálogo Ion de Platón. En este diálogo, Platón sostiene que el talento creador del artista no posee un origen ni un carácter racional. Esto ha movido a algunos intérpretes, concretamente a quienes ven en la razón la más alta facultad humana, a entenderlo como una desvalorización de las obras del arte para el desarrollo espiritual del hombre. Pero Grassi observa que en el diálogo el artista no aparece movido por la razón sino por una divinidad, es decir, para ponerlo en lenguaje algo más moderno, por una fuerza misteriosa y superior a la racionalidad humana ${ }^{8}$. La poesía y el arte cobran así su autonomía y recuperan plenamente su valor para la formación del hombre. No se trata de mero subjetivismo sino de mundos poseedores de leyes propias que el hombre debe descubrir.

La moral y la política con sus respectivos mundos constituyen aquí una unidad no porque posean el mismo tema sino porque ambas trabajan en el mismo campo, a saber, el de la acción humana en el individuo o en la comunidad. Hay una objetividad peculiar en las disciplinas que tratan esta modalidad del mundo humano. No se trata de creaciones subjetivas, sino de creaciones que poseen una objetividad diferente de la objetividad científica. De hecho, una "ciencia moral" y una "ciencia política" no existen en el sentido de poseer principios indubitables y conclusiones verdaderas. Para apoyar esta afirmación es suficiente recordar que la concepción del hombre y de la política sostenida por Aristóteles en su Política se funda en la admisión de que el hombre es por naturaleza un ser social; pero Hobbes construyó siglos más tarde su pensamiento político negando claramente el supuesto aristotélico y declarando en su Leviatán que naturalmente cada hombre no es social sino, por el contrario, un enemigo de todos los hombres restantes: guerra de todos contra todos, bellum omnium contra omnes. Y ambos planteamientos, el de Aristóteles y el de Hobbes, resultan al

${ }^{8}$ Ernesto Grassi, Verteidigung des individuellen Lebens. Studia humanitatis als philosophische Überlieferung, 1946, pp. 35 ss. 
fin perfectamente consistentes dentro de su respectivo sistema. Puras verosimilitudes.

Respecto del mundo de las creencias religiosas y de su correspondiente lenguaje, parece evidente que éste no es "verdadero" en el sentido cartesiano, es decir, no consiste en deducciones a partir de un principio que no puede ser revocado en duda, sino que su punto de partida se encuentra en la revelación, esto es, en una interpelación que se le muestra al creyente como originada en y dependiente de una realidad trascendente capaz de dotar a la existencia humana de sentidos totalizantes. (Para el no creyente, el lenguaje religioso no es sino una forma del lenguaje poético). En este contexto no deberíamos hablar de "verdades" religiosas sino más bien de "creencias", recordando que las creencias suelen ser más importantes, más ricas en consecuencias y más firmes que las ideas verdaderas, tal como lo ha mostrado en un ensayo José Ortega y Gasset. Para persuadirse de ello basta considerar cuántos seres humanos, muchos de ellos de alta espiritualidad, han dado y continúan dando sus vidas por sus creencias religiosas, pero ninguno de ellos daría seguramente ni una gota de sangre por una ley científica, por importante que ésta fuese.

Al final mencionamos el lenguaje cotidiano como apertura de un mundo de lo verosímil. Supongo que no cabrá duda alguna acerca de la gran importancia de esta perspectiva, toda vez que el lenguaje de todos los días es el soporte sobre el cual es posible construir los otros tipos de lenguaje.

En los casos de los diversos mundos y lenguajes considerados en este apartado se habla de verosimilitudes, no de verdades. Los discursos retóricos, que giran en torno a estas verosimilitudes, procuran en mayor o menor medida conmover los ánimos de sus auditores/lectores, tal como lo hacía la antigua retórica. A continuación quisiera mostrar cómo puede desarrollarse una disciplina objetiva a partir de verosimilitudes, y para hacerlo utilizaré como ejemplo una reflexión del mismo Grassi acerca de la realidad política.

\section{El mundo de lo político}

Los conflictos bélicos del siglo XX nos han enseñado en qué medida y con qué brutalidad las situaciones políticas de los pueblos pueden amenazar las vidas, las fortunas y el bienestar de innumerables 
seres humanos. Lo político revela así un poder que se ejerce sobre todos los individuos, a diferencia del arte, por ejemplo, que suele ser dejado para la producción, el goce y el uso de unos pocos. Ello no obstante, el mundo de lo político no está edificado sobre leyes de cumplimiento inevitable sino que depende de las sorpresas que permanentemente depara la libertad humana.

Parece cosa clara que lo político sólo puede darse en una comunidad humana. Ya Aristóteles se había preguntado qué es lo que caracteriza a dicha comunidad y la distingue de un rebaño u otra forma de agrupamiento animal. Su respuesta es decisiva: mientras los demás animales cuentan en el mejor de los casos con voz (phoné) para exteriorizar su placer o su dolor, el hombre posee el lenguaje (logos) para expresar lo justo y lo injusto, lo bueno y lo malo, lo provechoso y lo nocivo. En efecto, el mundo humano posee conceptos y valores que están fuera del alcance del animal. La política no consiste entonces, como parecen creerlo algunas personas, en el esfuerzo por alcanzar un poder que pueda favorecer (o perjudicar) a un individuo o a su facción, sino más bien en el intento de realizar el bien en la vida de la comunidad. Por eso, pudo añadir Grassi, el quehacer político no consiste en la reflexión teórica acerca del poder y de su ejercicio, sino en la percepción de situaciones concretas que exigen determinadas conductas como respuesta a la manifestación del ser que tales situaciones revelan. La política no es, entonces, un modo del saber conceptual; no se sujeta a la necesidad ni posee validez universal. Por el contrario, su carácter es esencialmente histórico, porque las situaciones que debe evaluar son siempre diferentes y no pueden repetirse, dependiendo de las sorpresas que pueden seguirse de las impredecibles voluntades humanas.

La actividad política es eminentemente práctica; su independencia respecto de lo teórico, que posee carácter conceptual, se funda en que la apreciación de lo particular, propia del quehacer práctico, no puede alcanzarse mediante la teoría, que posee carácter universal. La correcta apreciación de lo particular en su singularidad es imposible si se pretende deducirla derivándola de enunciados universalmente válidos. Por otra parte, la evaluación de una situación determinada conduce a la concepción de medidas anticipatorias requeridas por ella; se alcanza, pues, mediante una peculiar experiencia capaz de configurar un futuro aún inexistente y, por tanto, irreal. Esta capacidad es la prudentia de los clásicos latinos y la virtù de Maquiavelo. La prudentia, la visión 
política anticipadora del futuro, no se alcanza gracias a la teoría, a los principios generales, como parecen haber pensado Sócrates y Platón; pero tampoco se logra mediante el despliegue de las pasiones y de los impulsos naturales, como pensaba el Trasímaco de la República platónica. Su origen es misterioso; nace de una solicitación originaria del ser que se hace manifiesta en la situación política concreta. Ella consiste, como la areté ("virtud") de los antiguos, en la capacidad de servirse de las oportunidades y circunstancias de manera tal que puedan surgir formas posibles y necesarias de la vida en común. Falta en Maquiavelo, sin embargo, la identificación precisa de una capacidad indispensable en la vida política, que fue señalada por un contemporáneo suyo pero menos conocido que él, Francesco Guicciardini. Éste critica a Maquiavelo su costumbre de citar constantemente a los romanos, como si las circunstancias de ellos fueran comparables con las de una época más tardía; porque, dice Guicciardini, "es un gran error hablar de las cosas del mundo indistinta y absolutamente, y por así decirlo, en conformidad con reglas; porque casi todas poseen distinciones y excepciones por la variedad de las circunstancias, que no se pueden adaptar a una misma medida; y estas distinciones y excepciones no se hallan escritas en los libros, sino que es preciso que las enseñe la discreción (discrezione)" "9. La "discreción" posee en este texto el significado tradicional de capacidad para percibir y apreciar lo particular, no lo universal.

De este modo alcanza Grassi una nueva determinación. Si bien es verdad que la actividad política nos concierne a todos porque a todos nos afecta de uno u otro modo, la discrezione, la capacidad de discernir las situaciones y valorarlas adecuadamente en función de sus exigencias políticas es una facultad que poseen pocos individuos, porque consiste en el talento para discernir lo objetivo de la situación. Hay una objetividad de la acción política, objetividad que no se desprende de principios teóricos, que no surge de la necesidad lógica ni de la validez universal, sino que es puesta de manifiesto a través de la subjetividad de algunos individuos capaces de discernir el verdadero significado de las situaciones históricas particulares. Lo objetivo que se realiza en la historia es el prevalecer e imponerse de las diversas fuerzas que influyen sobre la vida humana y sus iniciativas; es precisamente aquello que Maquiavelo

${ }^{9}$ Francesco Guicciardini, "Ricordi”, $\S \S 6$ y 110, en Francesco Guicciardini, Opere, 1953. 
llamó la fortuna, que no es la buena suerte sino más bien las situaciones concretas, el destino favorable o adverso con que ha de enfrentarse toda actividad política.

La situación objetiva se ofrece al pensamiento político como punto de partida de una reflexión comunicable mediante la palabra, el logos, y susceptible, por consiguiente, de ser realizada como tarea común. Pero la tarea sólo puede ser realizada cuando hay un designio, una pre-elección de la voluntad, por la cual se decide acerca de lo que aún no es, una intención que los griegos llamaron proaíresis. La proaíresis no es sólo pre-visión sino también respuesta a una determinada coacción que obliga a realizar algo que se quiere que llegue a ser. La acción política responde a un llamado que es a la vez exterior e interior y que nos saca de la indiferencia. La situación exterior nos apremia y exige de nosotros una respuesta originada en nuestra experiencia interna; la política llega a ser así un asunto de nuestro interés (inter-esse) que compromete a nuestro ser, es decir, algo que nos apremia y oprime entre la coacción de la situación y la obligatoriedad de nuestra respuesta. Lo político hace surgir "un mundo humano que no brota de una libre decisión de los individuos ni de una irrupción de su capacidad creadora, sino del impulso por corresponder a una coacción efectiva anunciada en las situaciones históricas concretas que jamás les son indiferentes" 10 .

Con lo dicho hemos procurado establecer cómo, para Grassi, el lenguaje racional y la filosofía racionalista deben compartir su lugar en el espectro mental humano con otros lenguajes y sus correspondientes mundos (un mundo de la vida cotidiana, un mundo de la acción individual o comunitaria, un mundo de la creación poética y artística, acaso también un mundo de la vida religiosa); estos mundos constituyen ámbitos independientes y autónomos de la manifestación de lo real, tienen objetos diferentes y leyes propias de cada cual. Ello no significa, sin embargo, que tales mundos se configuren arbitrariamente ni en forma caprichosa, porque cada uno de ellos posee una peculiar objetividad. Nada tiene de absurdo, entonces, que la filosofía pueda considerar a la retórica (entendida en su acepción más sana como disciplina de lo verosímil) como un aspecto propio e inseparable de ella misma.

${ }^{10}$ Ernesto Grassi, Verteidigung des individuellen Lebens, 1946, pp. 8889. 


\section{REFERENCIAS}

Grassi, E. Verteidigung des individuellen Lebens. Studia humanitatis als philosophische Überlieferung. Bern: Francke, 1946.

- Macht des Bildes: Ohnmacht der rationalen Sprache. Köln, 1970.

Die Macht der Phantasie. Königstein/Ts., 1979. (Traducción castellana: El poder de la fantasía, Barcelona: Anthropos, 2003).

- Rhetoric as Philosophy. The Humanistic Tradition. University Park and London: The Pennsylvania State University Press, 1980.

Vico and Humanism. Essays on Vico, Heidegger, and Rhetoric. New York: Peter Lang, 1990. (Traducción castellana, Barcelona: Anthropos, 1999).

"Il Problema del Logo", 1936. En E. Grassi, Primi Scritti 19221946, Vol. I. Napoli, La Città del Sole, 2011.

"Der Begin des modernen Denkens" [1940]. En E. Grassi, Primi Scritti 1922-1946, Vol. I. Napoli, La Città del Sole, 2011.

Guicciardini, F. "Ricordi”. En Francesco Guicciardini, Opere. Milano-Napoli: Riccardo Ricciardi Editore, 1953.

Vico, G. Obras. Oraciones inaugurales. La antiquísima sabiduría de los italianos. Barcelona: Anthropos, 2002.

- Ciencia nueva [1725]. Madrid: Tecnos, 1995. 